\title{
Increased oxidative/nitrosative stress and decreased antioxidant enzyme activities in prostate cancer
}

\author{
Zorica Arsova-Sarafinovska ${ }^{\mathrm{a}, 1}$, Ayse Eken ${ }^{\mathrm{b}, 1}$, Nadica Matevska ${ }^{\mathrm{c}}$, Onur Erdem ${ }^{\mathrm{b}}$, Ahmet Sayal ${ }^{\mathrm{b}}$, \\ Ayhan Savaser $^{\mathrm{b}}$, Saso Banev ${ }^{\mathrm{d}}$, Daniel Petrovski ${ }^{\mathrm{e}}$, Sonja Dzikova ${ }^{\mathrm{f}}$, Vladimir Georgiev ${ }^{\mathrm{e}}$, \\ Aleksandar Sikole ${ }^{\mathrm{f}}$, Yașar Özgök ${ }^{\mathrm{g}}$, Ljubica Suturkova ${ }^{\mathrm{c}}$, Aleksandar J. Dimovski ${ }^{\mathrm{c}}$, Ahmet Aydin ${ }^{\mathrm{b}, *}$ \\ ${ }^{a}$ Republic Institute for Health Protection, Department of Drug Quality Control, Skopje, Republic of Macedonia \\ ${ }^{\mathrm{b}}$ Gulhane Military Medical Academy, Department of Toxicology, Etlik, Ankara, Turkey \\ " University "St. Cyril and Methodius", Faculty of Pharmacy, Skopje, Republic of Macedonia \\ d University "St. Cyril and Methodius", Faculty of Medicine, Institute of Pathology, Skopje, Republic of Macedonia \\ ${ }^{\mathrm{e}}$ University Clinic of Urology, Skopje, Republic of Macedonia \\ ${ }^{\mathrm{f}}$ University Clinic of Nephrology, Skopje, Republic of Macedonia \\ ${ }^{g}$ Gulhane Military Medical Academy, Department of Urology, Etlik, Ankara, Turkey
}

Received 13 January 2009; received in revised form 29 April 2009; accepted 14 May 2009

Available online 22 May 2009

\begin{abstract}
Objectives: The study was aimed to evaluate the oxidative/nitrosative stress status in prostate cancer (CaP) and benign prostatic hyperplasia (BPH).

Design and methods: 312 men from two different populations were included: 163 men from Macedonia (73 CaP patients, $67 \mathrm{BPH}$ patients and 23 control subjects) and 149 men from Turkey (34 prostate cancer patients, $100 \mathrm{BPH}$ patients and 15 control subjects). We measured erythrocyte malondialdehyde (MDA) levels, erythrocyte activities of superoxide dismutase (CuZn-SOD), glutathione peroxidase (GPX) and catalase (CAT); plasma nitrite/nitrate $\left(\mathrm{NO}_{2}^{-} / \mathrm{NO}_{3}^{-}\right)$, cGMP and 8-hydroxy-2'-deoxyguanosine (8-OHdG) levels.

Results: A similar pattern of alteration in the oxidative/nitrosative stress-related parameters was found in both, Macedonian and Turkish studied samples: higher MDA concentrations with lower GPX and CuZn-SOD activities in CaP patients versus controls and BPH groups. The CAT activity was decreased in the CaP patients versus controls in the Turkish studied sample. Furthermore, CaP patients had increased plasma $\mathrm{NO}_{2}^{-} / \mathrm{NO}_{3}^{-}$and cGMP levels versus controls and $\mathrm{BPH}$ groups in both studied samples.

Conclusions: This study has confirmed an imbalance in the oxidative stress/antioxidant status and revealed an altered nitrosative status in prostate cancer patients.
\end{abstract}

(C) 2009 The Canadian Society of Clinical Chemists. Published by Elsevier Inc. All rights reserved.

Keywords: Prostate cancer; Oxidative stress; Antioxidant enzymes; Nitric oxide; Benign prostatic hyperplasia; 8-hydroxy-2'-deoxyguanosine

\section{Introduction}

Prostate cancer continues to be the most frequently diagnosed neoplasm, and the second leading cause of cancer-related

Abbreviations: CaP, prostate cancer; MDA, malondialdehyde; CuZn-SOD, copper zinc superoxide dismutase; CAT, catalase; GPX, glutathione peroxidase; $\mathrm{NO}_{2}^{-} / \mathrm{NO}_{3}^{-}$, nitrite/nitrate; cGMP, cyclic guanosine monophosphate; $8-\mathrm{OHdG}$, 8-hydroxy-2'-deoxyguanosine; ROS, reactive oxygen species; RNS, reactive nitrogen species; RO', alkoxyl radical; ROO', peroxyl radical; PSA, prostate specific antigen; PIA, proliferative inflammatory atrophy; $\mathrm{NO}^{\circ}$, nitric oxide.

* Corresponding author. Fax: +90 3123046091.

E-mail address: ahmetaydin30@hotmail.com (A. Aydin).

1 These authors contributed equally to this paper. mortality in men [1]. The cause of this disease is not well understood; however, certain factors are commonly linked to its development. Nonmodifiable risk factors include age, race, and genetic/family history; diet is a modifiable risk factor [2].

Oxidative stress is an inevitable consequence of aerobic life. Growing evidence indicates that the cumulative production of reactive oxygen (ROS) and nitrogen species (RNS) through either endogenous or exogenous insults plays a major role in the aging process and age-related diseases such as prostate cancer $[3,4]$. Oxygen radicals are associated with different steps of carcinogenesis, either through structural DNA damage, interaction with oncogenes or tumor suppressor genes or immunological mechanisms [5]. In addition, oxygen radicals may also 